\title{
BIOGRAFIA OU DECLARAÇÃO DE AMBIÇÃO FILOSÓFICA: COMO LER ECCE HOMODE NIETZSCHE?
}

Lúcia Schneider Hardt ${ }^{1}$

\section{Resumo}

O artigo discute o livro Ecce homo, de Nietzsche, afirmando que o texto é uma interpretação do próprio filósofo sobre seu pensamento, não para dar ao livro um tom sagrado, tampouco para destacar sua biografia, mas para afirmar um pensamento dissonante e expor sua ambição filosófica. Sem constrangimentos, Nietzsche apresenta seus conflitos, suas paixões, decepções, anuncia uma dimensão trágica da vida que não se conduz pelo pessimismo, mas pela alegria de viver intensamente, inclusive enfrentando o sofrimento como uma das faces da vida. Sua filosofia é oriunda de uma vida em constante devir, transfigurada a partir de experiências que promovem o cultivo de si e a possibilidade de "tornar-se o que se é" por meio da "aplicação" de seu próprio método genealógico.

Palavras-chave: Ecce homo; Ambição filosófica; Genealogia; Cultivo de si

\section{INTRODUÇÃO}

Em julho de 2012, conheci a Universidade Técnica de Berlim buscando estabelecer alguns contatos na perspectiva de um pós-doutorado ou uma capacitação de curta duração.

\footnotetext{
${ }^{1}$ Doutora em Educação pela Universidade Federal do Rio Grande do Sul - UFRGS, Professora Associada I da Universidade Federal de Santa Catarina - UFSC. Endereço: Rua das Cerejeiras 186, casa 8, Bairro Carvoeira, Florianópolis-SC, Brasil. CEP 88040510. Endereço eletrônico: luciashardt@gmail.com.br
} 
Estabeleci contato com o professor Helmut $\mathrm{Heit}^{2}$, que prontamente, aceitou dialogar e abriu espaço para a participação de um Colóquio sobre Nietzsche na Universidade. O artigo inicia com este traço, pois o conteúdo que será desenvolvido tem uma relação direta com este Colóquio e o debate que tive a oportunidade de participar. Vou tomar as ideias desse momento, acrescentar as minhas para colocar na roda um problema: Como ler um autor e o que fazer com ele quando o que se lê, perturba, ainda que tenha sido escolhido para estudar?

Ainda que eventualmente a língua possa ter me confundido em algumas relações e compreensões, prefiro arriscar torná-las públicas para refletir sobre o tema e discutir sua pertinência.

O livro referência no colóquio foi Ecce homo, e a problematização levantada pelo coordenador partiu de uma provocação: Como andamos lendo Nietzsche, quais são alguns dos equívocos mais comuns? Desta provocação à relação com o próprio livro-referência. Segundo Heit (2012), Ecce homo é muito antes, a apresentação de uma ambição filosófica que uma biografia. Desta afirmação desdobraram-se muitas outras perguntas aos participantes do Colóquio, um grupo pequeno de estudantes e professores, mas extremamente interessado em entender a tese apresentada pelo coordenador. Resolvi escrever este artigo provocada também por esta tese. Algumas das perguntas compartilhadas:

- Será que já pensamos sobre as diferentes formas possíveis de ler Nietzsche?

- Como ele próprio se leu?

- Teria ele em alguns momentos lido a si mesmo de forma equivocada?

- Ao lê-lo, reconhecemos que ele diz tolices, erra, se suja, se arrepende, se desculpa, ou insistimos em vê-lo como um teórico coerente, acima de qualquer suspeita?

- Com que Nietzsche quero ficar como leitor?

- Reconheço que não entendi ainda plenamente suas ideias?

Por fim, uma recomendação: talvez seja necessário ler o que Nietzsche quis dizer $e$ não o que seria bom ouvir.

Desse ponto muitas reflexões passaram a ser pronunciadas no Colóquio, o que em parte levou ao conceito de interpretação. Interpretar e ler Nietzsche é um movimento sem parada, não tem ponto de esgotamento. Já foi possível entendê-lo a partir de sua vivência

\footnotetext{
${ }^{2}$ Doutor em Filosofia pela Universidade de Hannover com um texto sobre a reconstrução da gênese da Filosofia na Grécia Antiga. Pós-doutorado no Departamento de Filosofia da Universidade da Califórnia em San Diego. Desde outubro de 2007 exerce a função de pesquisador (Bolsas Dilthey) no Instituto de Filosofia, Filosofia da Ciência, História da Ciência e Tecnologia da Universidade Técnica de Berlim.
} 
como filólogo, anticristão, antissistemático, psicólogo, mas ainda assim essas não são condições suficientes para compreendê-lo. "É preciso ler Nietzsche pela filosofia", diz Heit. Ler o seu texto para achar o autor. Descobrir as peles que o fizeram filósofo. Certamente, a de psicólogo, assim como de um curioso pela fisiologia porque interessado na vida que pulsa, que pensa, que enfrenta, que arrisca. Igualmente, descobrir o que pode nos irritar, descobrir se estou fascinado ou pronto a rejeitá-lo. A filosofia exigirá uma leitura implicada por alguns rigores do campo, que não são algemas, mas terreno fértil dos próprios conceitos que desejo compreender. Entender quando e por que descarto coisas que estão no texto do autor. Não revelo, não divulgo. Recortar um texto a seu gosto é descartar a filosofia como recurso de leitura. Não convém ser excessivamente dogmático, mas também não desenvolver delírios interpretativos. O texto não cansa de ser lido, ele sempre nos convida de novo para a interpretação. Pode ser um ato solitário ou coletivo. Um pesquisador tende, por vezes, a dizer que já compreendeu um autor, nada ficou por dizer, o que empobrece a curiosidade humana.

\section{O CONTEÚDO DE ECCE HOMO}

Deste ponto, o coordenador volta à sua provocação: Como um homem pode avaliar a si mesmo? Ecce homo não é autobiografia, não é psicologismo, não é introspecção, não é a narração do drama de uma vida. Não é também a reedição de uma espécie de ato e potência que descreveria a perturbação de um caminhante em direção à sua boa e perfeita forma.

O que ele diz de si mesmo no livro, tem a ver com filosofia. Trata-se de uma declaração de sua ambição filosófica. Ambição enquanto sentido filosófico, apontando sua trajetória como pensador ao afirmar que filosofia se faz com o martelo.

Ambição no sentido de quem fala de si para declarar seu propósito: enfrentar a mentira daqueles que falam em melhorar a humanidade. Nesses termos, a guerra é contra a moral, contra uma ideia de homem bom, tido como superior em função da capacidade de ser generoso e benevolente. A condição da existência dos homens bons, segundo Nietzsche,

é a mentira -: expresso de outra maneira, o não-querer-ver a todo preço como a realidade é no fundo constituída, ou seja, não de modo a sempre provocar instintos benevolentes, menos ainda de modo a sempre admitir a interferência de mãos míopes e simplórias. Considerar as misérias de toda espécie como objeção, como algo que é preciso abolir, é a niaiserie [tolice] par excellence, em sentido geral uma verdadeira desgraça em suas consequências, uma fatalidade de estupidez -, quase tão estúpida quanto seria a vontade de abolir o mau tempo - por compaixão aos 
pobres digamos... Na grande economia do todo, os horrores da realidade (nos afetos, nas cobiças,na vontade de poder) são incalculavelmente mais necessários do que aquela forma de pequena felicidade que se denomina "bondade"; é preciso mesmo ser indulgente para esta última conceder absolutamente um lugar, pois é condicionada pela mendacidade de instinto. (NIETZSCHE, 2008, p. 104).

Dessa indignação configura-se uma filosofia que necessita também descrever o homem que teve a coragem de percorrer esse caminho e apontar como o caminho sempre de novo impõe desafios e exige novos olhares. "Como tornar-se o que se é" implica querer ver o mundo como é, não mascará-lo com mentiras, tomar a vida como vontade de potência, não se deixar capturar por uma filosofia medíocre, cultivar-se para manter-se presente na vida, fazer a vida vingar, afirmar-se, saber esquecer, enfim, ser o oposto de um décadent.

\section{O HOMEM QUE SE TORNOU FILÓSOFO}

O debate para pensar Ecce homo, mais que uma apresentação de argumentos, deixou a cada participante do Colóquio um problema a ser pensado. Assim, tomo o problema para pensar de novo sobre o que ficou exposto, procurando ler o autor e os textos sem prévias defesas ou ataques, mas tentando ler Nietzsche a partir dele mesmo, inclusive com aquilo que pode perturbar, impactar.

O livro já começa afirmando que o autor prevê que será necessário dizer quem é para que a humanidade possa entender sua obra. "A pequenez de seus contemporâneos" (2008, p. 15) impediu qualquer atenção a suas ideias. Afirma não ser um monstro moral, apenas insiste em afirmar que "a última coisa que eu prometeria seria melhorar a humanidade" (2008, p. 15). Tem como propósito derrubar ídolos, ideais e deseja apresentar o quanto de coragem é necessário para enfrentar supostas verdades. Enfrenta o mundo organizado com acidez, com dureza, com ironia, por vezes, cinicamente. Ficamos impactados com seus métodos, preferindo, às vezes, omitir palavras, fragmentos de texto e supervalorizar outros. De novo, as perguntas já postas: Por que destacar no autor apenas o que quero ouvir? Por que é tão difícil incorporá-lo como é? Afinal, o que acontece comigo enquanto leitor quando leio o que não gostaria de ver? Por vezes, até ele mesmo se leu mal, fala de si, inadequadamente.

A vida vista de perto, tomada no seu limite, produz uma obra, um texto, que não termina na experiência pessoal, na vida contada, apenas começa. Não é então uma biografia 
apenas, mas uma vida que cria filosofia. As diferenças não o fazem deixar de ter boas lembranças da sua vida, demonstrar afetos, mas mais do que passar pela vida, Nietzsche deseja pensar sobre a vida. O inverno, o frio, a chuva, comidas, cheiros, indicam reflexões, impõem pensamentos. A dor estabeleceu bases para sua melhor filosofia. Afirma ele que:

\begin{abstract}
Necessito dizer, após tudo isso, que sou experimentado em questões de décadent? Conheço-a de trás para frente. Inclusive aquela arte de filigrama do prender e apreender, aqueles dedos para nuances, aquela psicologia do ver "além do ângulo", e o que mais me seja próprio, tudo foi então aprendido, e a verdadeira dádiva daquele tempo em que tudo em mim se refinava, tanto a observação mesma como os órgãos da observação. Da ótica do doente ver conceitos e valores mais sãos, e, inversamente, da plenitude e certeza da vida rica descer os olhos ao secreto lavor do instinto de décadence - este foi o meu mais longo exercício, minha verdadeira experiência, se em algo vim a ser mestre, foi nisso. Agora tenho-o na mão, tenho mão bastante para deslocar perspectivas: razão primeira por que talvez somente para mim seja possível uma “tresvaloração dos valores". (NIETZSCHE, 2008, p. 22).
\end{abstract}

Sua ambição filosófica começa a ser delineada - transvaloração dos valores - conduta de um guerreiro. Um guerreiro que reconhece o inimigo, mas quer atacá-lo. Exige uma natureza forte e uma prática de guerra que Nietzsche resume em quatro princípios:

\footnotetext{
Primeiro: ataco causas vitoriosas - ocasionalmente, espero até que sejam vitoriosas. Segundo: ataco somente causas em que não encontraria aliados, em que estou só em que me comprometo sozinho... Nunca dei um passo em público que não me comprometesse - este é o meu critério do justo obrar. Terceiro: nunca ataco pessoas - sirvo-me da pessoa como uma forte lente de aumento com que se pode tornar visível um estado de miséria geral porém, dissimulado, pouco palpável. [...] Quarto: ataco somente coisas de que está excluída qualquer diferença pessoal, em que não existe pano de fundo de experiências ruins. Pelo contrário, atacar é em mim prova de benevolência, ocasionalmente gratidão. (NIETZSCHE, 2008, p. 29-30).
}

Ainda que um texto autobiográfico, que contém o tempero de um retrospecto da vida, uma perspectiva contemplativa de si mesmo, o conteúdo do Ecce homo descreve uma vida como obra de arte, descreve um homem que ama seu destino, soube compreender a dimensão trágica da vida e mais, deseja criar valores que possam trazer novas auroras para a humanidade. Precisa de solidão, seu Zaratustra é um ditirambo à solidão. Nessa guerra, muitas coisas escritas parecem inconvenientes, alguns argumentos são grosseiros, outros não compreendemos.

Para apresentar sua ambição filosófica, Nietzsche avalia sua própria obra. Inicia com o Nascimento da tragédia, um livro implicado pela arte, pelos gregos e pela cultura alemã. $\mathrm{O}$ próprio autor diz que para ser justo com esta etapa é preciso esquecer algumas coisas. Ele 
HARDT, Lúcia Schneider .

mesmo na reedição da obra, escreve um prólogo sobre os problemas do texto, sobre as influências que depois rejeita, mas também reafirma duas decisivas novidades: a compreensão do fenômeno dionisíaco nos gregos e a compreensão de Sócrates. O ataque a Sócrates é o foco central do texto, revela um duelo: entre o instinto e a racionalidade. A filosofia também moraliza e reedita uma forma de decadência. A racionalidade reduz a beleza da arte, da tradição grega, da dimensão trágica, do valor da música. O livro é em parte a expressão da metafísica do artista imaginando criar no contexto alemão o vigor da arte grega. $\mathrm{O}$ autor fareja que quando o instinto degenera, ele se volta contra a vida, consegue identificar alguns exemplos, o mais forte: Sócrates. Posteriormente, verifica que o fenômeno repete-se com Wagner e Schopenhauer. Ainda assim o perfil do primeiro filósofo trágico já está em processo, enfrentando seu inimigo: o filósofo pessimista ou, em outras palavras, racional.

O desejo de Nietzsche indica uma vontade de afirmação de um perfil filosófico temperado já em sua primeira obra, pela perspectiva trágica/dionisíaca e que vai ganhando força com outros elementos que a própria vida na forma de experiência vai oferecer. Assim:

\begin{abstract}
A afirmação do fluir e do destruir, o decisivo numa filosofia dionisíaca, o dizer Sim à oposição e à guerra, $o$ vir a ser, com radical rejeição até mesmo da noção de "Ser" - nisto devo reconhecer, em toda a circunstância, o que me é mais aparentado entre o que até agora foi pensado. A "doutrina do eterno retorno", ou seja, do ciclo absoluto e infinitamente repetido de todas as coisas - essa doutrina de Zaratustra poderia afinal ter sido ensinada também em Heráclito. Ao menos encontram-se traços dela no estoicismo, que herdou de Heráclito quase todas as ideias fundamentais. (NIETZSCHE, 2008, p. 62).
\end{abstract}

Nietzsche fala de sua promessa em oferecer à humanidade uma era trágica, o que significa dizer sim à vida, que ainda não foi totalmente percebida e descrita em sua primeira obra, mas já está presente um cultivo desta ideia, que é já um sinal de sua filosofia.

Do limite da primeira obra nascem as extemporâneas, que são guerreiras e o primeiro ataque é contra a cultura alemã. A este tema Nietzsche dedica-se com sarcasmo, cinismo, ironia, excessos. Demonstra desprezo pela cultura alemã, que já está equivocada nos estabelecimentos de ensino. Contra eles, seu primeiro ataque. Depois, o entendimento da história e seu uso inadequado que barbariza o que dela se diz retirar. A terceira e a quarta extemporâneas terminam por rejeitar modelos de cultura dados como mais sofisticados para redescobrir um conceito de cultura pautado pelo cultivo de si. 
A ideia do cultivo de si é, por excelência, uma ideia filosófica oriunda dos gregos, mas um problema de educação. Foi convertida pelos estabelecimentos de ensino em erudição, em submissão a um idealismo moralista. O cultivo de si implica dureza consigo, defesa de si, um vir a ser que, no caso de Nietzsche, envolve um compromisso com a filosofia. Afirma:

\begin{abstract}
O que hoje sou, onde hoje estou - em uma altura de onde já não falo com palavras, mas com raios -, ó quão longe disso eu ainda estava então! - Mas eu via a terra não me enganei um instante sobre caminhos, mares e perigos - e sobre o êxito! A grande paz no prometer, o feliz mirar em um futuro que não permanecerá mera promessa! - Ali cada palavra vivida, profunda, interior; os sofrimentos maiores estão presentes, existem palavras cobertas de sangue. Mas um vento de grande liberdade sopra sobre tudo; a própria ferida não é sentida como obstáculo. (NIETZSCHE, 2008, p. 67).
\end{abstract}

Para Nietzsche, um filósofo é um corpo explosivo, que corre perigos em função dos ataques que faz. O sentimento de distância em relação aos filósofos notáveis de seu tempo, o obrigam a ser cada vez mais forte para enfrentá-los. Ele mesmo diz que por um tempo teve que ser erudito em função de sua ambição filosófica.

Para enfrentar os perigos um livro para espíritos livres. Humano, demasiado humano é um livro com textos de libertação das coisas contrárias à natureza de Nietzsche. O espírito livre tem uma relação direta com a ideia "cultivo de si", que significa um espírito forte capaz de "conhecer todos os esconderijos onde o ideal faz sua morada - onde tem suas masmorras e sua última trincheira" (NIETZSCHE, 2008, p. 69). O livro volta-se às ciências, à físiologia, para inclusive entender melhor o instinto. O livro testemunha também as decepções do autor com Wagner, com a cultura alemã, com o poder. Percebeu que desperdiçou tempo em coisas erradas, a função de filólogo, o desvio de seu propósito filosófico, era hora de retornar a si mesmo e com liberdade. Foi tomado de uma "impaciência consigo mesmo" e, de repente...

\footnotetext{
Uma sede abrasadora me tomou: a partir de então ocupei-me apenas de fisiologia, medicina e ciências da natureza - mesmo a autênticos estudos históricos retornei somente quando a tarefa a isso me obrigou imperiosamente. Foi então que atinei também pela primeira vez a relação entre uma atividade escolhida contra o próprio instinto, uma assim chamada "profissão", que é o que menos professamos - aquela necessidade de entorpecimento da sensação de vazio e de fome através da arte de Wagner. [...] Naquela época, meu instinto decidiu-se inflexível pelo fim daquele ceder, seguir, confundir-se com outros. Qualquer espécie de vida, as condições mais desfavoráveis, doença, pobreza - tudo me pareceu preferível àquela indigna "falta de si", na qual havia caído por ignorância, por juventude, e na qual havia depois permanecido por letargia, pelo chamado "sentimento do dever". (NIETZSCHE, 2008, p. 71-72).
} 
HARDT, Lúcia Schneider .

Esta revisão de postura, avaliação de si mesmo, fez da solidão um momento privilegiado. Precisava pensar, esquecer, esperar para criar. Esta trajetória da revisão de si fez surgir $O$ andarilho e sua sombra e Aurora, por exemplo. Assim, Humano demasiado humano é um livro com teor científico. Retoma efetivamente o conceito de ciência, bastante marginalizado pelo sentimento do belo, da arte. Representa uma disciplina máxima de estudo para, por fim, afirmar que a ciência é também uma expressão da arte. Arte do conhecimento do corpo, de seus instintos, de sua fisiologia. Deste ponto começa a luta de Nietzsche com mais vigor contra a moral. O livro Aurora deseja mostrar o que ficou impedido pela moral e ensina a dizer sim a tudo que foi desprezado e proibido. Um "grande meio dia" fica anunciado, quando o ser humano consegue livrar-se dos domínios da moral e leva às últimas consequências, a indagação sobre os valores. Deve enfrentar as lições do sacerdote, do filósofo para não se deixar capturar pelas armadilhas "das melhores mãos". Afinal,

\footnotetext{
quando se retira a seriedade da autoconservação, da fortificação do corpo, ou seja, da vida, quando se faz da anemia um ideal, do desprezo ao corpo a "salvação da alma", que é isto, senão uma receita de décadence? - A perda de centro de gravidade, a resistência aos instintos naturais, em uma palavra, a "ausência de si" - a isto se chamou moral até agora... Com Aurora iniciei a luta contra a moral da renúncia de si. (NIETZSCHE, 2008, p. 77).
}

Em Gaia Ciência, Nietzsche procura estabelecer uma relação entre o conceito de ciência e a beleza da cultura provençal, reunindo beleza, sofisticação e conteúdo para polemizar e abolir as tradicionais oposições entre verdade e mentira, estendendo este debate entre filosofia e ficção. Nesse texto, o espírito livre vincula-se a um corpo artístico que já começa a ensaiar os primeiros passos de uma dança que se concretiza com Zaratustra.

O pensamento do eterno retorno está em todo canto da obra Zaratustra, afirmado pelo gosto do autor em forma de arte, de música, contornado pela dimensão trágica que recupera os gregos em sua mais bela forma. A dor não é um impedimento da vida, a dor ensina a viver, na grande maioria das vezes, sofistica o viver. Nessa declaração um ataque ao idealismo, aos homens que tentaram melhorar a humanidade com promessas de um mundo inexistente, insistindo com a negação dos instintos, dos desejos, do corpo, da terra. Para compreender isso, é preciso conhecer da fisiologia do corpo, da grande saúde, que nunca é alcançada definitivamente, mas é preciso buscá-la constantemente. Nesses termos, a humanidade está 
marcada pela mediocridade, acreditou no mundo ideal, deu as costas ao mundo real e perdeu de viver as mais belas formas.

A ideia de super-homem, além homem, implica enfrentar este humano medíocre para oferecer-lhe outras possibilidades de vida. O livro passa por etapas distintas, até que o próprio Zaratustra se percebe consumido pela ideia de converter o outro, mas em tempo escapa desta lógica, e como um dançarino que tem pés ligeiros, ensaia outros passos, outras músicas, a linguagem do ditirambo, a vontade de potência. Para viver a experiência do além homem, o martelo é instrumento fundamental, implica o prazer em destruir para poder criar. "Em alguma medida," - diz Nietzsche - "todo criador precisa ser duro e afirmar seu querer, seu viver e seu devir." O martelo surge como instrumento e seguirá nas obras seguintes como expressão de sua filosofia.

Para além do bem e do mal é uma obra que faz uma crítica da modernidade, com tom sofisticado enfrentando a dimensão dos valores e de como eles ganham concretude e espaço na vida das pessoas. Indica uma filosofia para o futuro pautada pela coragem de um pensamento capaz de resistir ao seu tempo e à sua história quando se faz necessário. Segue o escrito polêmico - Genealogia da Moral - composto por três dissertações, a primeira enfrentando o ressentimento fruto da psicologia do cristianismo; a segunda aborda a questão da psicologia da consciência que se converte numa espécie de instinto de crueldade que se volta contra o homem por não conseguir expulsar aquilo que o perturba. A terceira dissertação foca a reflexão sobre o ideal ascético, sempre defendido como pressuposto nobre, contudo, na avaliação de Nietzsche, um ideal de décadence. Nesta obra está fortemente indicada a meta filosófica de Nietzsche: a transvaloração de todos os valores.

O martelo do filósofo retorna com a obra Crepúsculo dos ídolos e torna-se uma ferramenta para combater o idealismo, a verdade. As ideias modernas são mais senis que as antigas e o filósofo se vê como um mensageiro de uma nova cultura, de um outro destino. Posições presunçosas, mas imbuídas de uma convicção que não suporta desperdiçar o ar livre, o caminho para cima fruto de um pensamento indomável.

No Caso Wagner, Nietzsche retoma o debate em torno da música, também em decadência em função do idealismo e sempre mais distante da flauta de Dionísio. Fica reconhecido o valor de Wagner, mas fica expressa uma indignação com a escolha que o músico faz: servir o Estado. O livro ainda apresenta uma crítica feroz ao gosto alemão, às 
HARDT, Lúcia Schneider .

práticas religiosas, tanto católicas quanto luteranas e sintetiza: "os alemães são uns idealistas" (NIETZSCHE, 2008, p. 98).

\begin{abstract}
A narrativa das obras termina, e mais um texto surge: por que sou um destino. Nesta abordagem fica indicada sua meta: Um dia, meu nome será ligado à lembrança de algo tremendo - de uma crise como jamais houve sobre a Terra, da mais profunda colisão de consciências, de uma decisão conjurada contra tudo o que até então foi acreditado, santificado, requerido. Eu não sou um homem, sou um dinamite. (NIETZSCHE, 2008, p. 102).
\end{abstract}

Parece que ao final da obra Ecce homo fica delineada mesma uma ambição filosófica, que não deseja dirigir-se às massas, dá as costas aos crentes, e jamais imagina ser classificado como santo. Nesses termos empenha-se em ganhar antipatias, em produzir impactos, gerar aversões para jamais ser confundido com um idealista. É um filósofo que, por vezes, nos entristece, talvez mais, nos aborrece com o que diz. Temos a tendência de evitar revelar o que nos incomoda, mas como já afirmamos no início do texto, ler Nietzsche implica também digerir o que não compreendemos, o que não gostamos, o que rejeitamos. Um autor não é para ser consumido e convertido em peça publicitária, mas um pensador tem como tarefa nos fazer tombar, em certa medida viver a transvaloração dos valores e suportar o que a experiência vai nos exigir.

Zaratustra acaba sendo uma expressão da filosofia de Nietzsche, uma vez que incorpora as experiências vividas pelo autor, chegou a entusiasmar-se com a plateia, habitou a praça pública, foi rejeitado, e percebe que sua tarefa é outra. Não deseja mais convencer, classificar, apontar, caindo nas teias do otimismo que, ao fim e ao cabo, é também decadente. Zaratustra combate a moral, aquela inventada pelos homens para castrar os instintos da humanidade. Afinal,

tudo o que se chamava "verdade" é reconhecido como a mais nociva, pérfida e subterrânea forma de mentira; o sagrado pretexto de "melhorar" a humanidade como ardil para sugar a própria vida, torná-la anêmica. Moral como vampirismo... Quem descobre a moral descobriu com isso o não-valor dos valores todos nos quais se acredita ou se acreditou; nada mais vê de veneração nos tipos mais venerados e inclusive proclamados santos, neles vê a mais fatal espécie de aborto, fatais porque fascinavam... (NIETZSCHE, 2008, p. 108).

Ecce homo é uma interpretação do próprio filósofo sobre sua obra, não para imortalizar-se, mas para afirmar um pensamento tão dissonante a ponto de ser rejeitado. Não tem constrangimento em apresentar seus conflitos, suas paixões, decepções e anuncia uma 
dimensão trágica da vida que não se conduz pelo pessimismo, mas pela alegria de viver o que de fato a vida é, inclusive enfrentando o sofrimento como uma das faces da vida. Sua filosofia é oriunda de uma vida em constante devir, transfigurada a partir das vivências e de como estas experiências promovem o cultivo de si.

A afirmação do cultivo de si ancora-se na ideia do pathos e não da ação. Não se determina racionalmente uma vivência, mas avalia-se o vivido e sua capacidade de produzir o pathos de excesso. Nietzsche utiliza ainda a metáfora do jardineiro ao afirmar que quanto mais vivência, mais somos capazes de garantir um solo para outras bem como evitar o nascimento de espécies indesejáveis. Tornar-se o que se é implica reconhecer esta aventura do cultivo de si que apresenta também uma dimensão ética e estética. O acesso racional à vida, é impossível, cabe assumir sua dimensão estética, trágica, para enfrentar a vida em seu excesso, em sua abundância. A dor, a crise, a rejeição, a doença não são planejadas, mas devem ser enfrentadas uma vez que a vida se apresenta também com esta face. E nesse excesso de vida, nestas diferentes travessias, aparece um ser humano ético, capaz de compreender como a vida pode se apresentar para tantos outros.

O que se vive pode ser avaliado, entra em cena a genealogia de Nietzsche, capaz de fazer o ser humano ruminar, escavar as vivências para selecionar aquelas que deseja cultivar em seu "jardim".

Em Ecce homo, Nietzsche vai às últimas consequências, pois não quer ser de outro modo do que aquele que fica confirmado quando da apresentação do livro. Rejeita qualquer espécie de intencionalidade, nada foi planejado para assim se fazer, e mesmo assim nada precisa ser modificado. O que fica afirmado é o que Nietzsche deseja ser, reconhecendo quão suas vivências o fizeram diferente, mas agora este que aparece é o mesmo quer viver. Jamais ser santificado, seria absolutamente detestável, mas ser reconhecido como um filósofo que tinha que ser assim. Enfim, um filósofo-destino. O destino que rejeitou a culpa, a formação inicial, levou às últimas consequências a curiosidade, derreteu a solidez de qualquer noção de reputação bem como de hábitos duradouros (VIESENTEINER, 2011).

Ter espírito livre significa ser fiel a si mesmo, suportar a brevidade de nossas condutas, já que a vida sem qualquer antecipação nos alcança vivências que nos obrigam a pensar novamente.

A solidez, a insistência com imagens e conceitos fixos, a crença na virtude inviolável, são atitudes impróprias para um filósofo. Um filósofo-jardineiro que, a rigor, sempre tem uma 
ideia de estética, precisa estar habilitado para criar outras paisagens, renunciar aos hábitos vigentes, dar à beleza outra dimensão. $\mathrm{O}$ ato criativo tende a ser incompreendido, o que em parte justifica a originalidade do criador. A falta de compreensão em relação à filosofia de Nietzsche, em alguma medida, justifica sua condição solitária, mas, sem dúvida, também sua originalidade.

Em muitos momentos Nietzsche anuncia ter necessidade de solidão e gosto pelas alturas. A distância, a solidão permite sua crítica feroz à modernidade para analisar e avaliar $a$ décadence de sua época. Mas a solidão não deve impedir a afirmação da sua filosofia, de diferenciar-se do seu tempo, de apresentar sua ambição filosófica. Esta parece ser a intenção do Ecce homo. O falar de si não tem um sentido apenas autobiográfico, mas a descrição de vivências significativas que o obrigaram a pensar mais e sempre sobre o ser humano, transfigurando sua vida, seus conceitos e sua crítica. Surge a obra de arte, que neste livro significa anunciar a filosofia de Nietzsche para outros tempos.

Não sou um homem, sou uma dinamite (NIETZSCHE, 2008, p. 102), não quero crentes, desejo antes de tudo uma vida abundante ao ser humano, capaz de compreender que viver pode ser interessante ainda que não possamos controlar e regular nossas próprias vivências.

A empreitada de Nietzsche foi alcançada. As travessias de um homem afirmam uma filosofia que tardiamente ganha notoriedade. Não surgiu o santo, o herói, mas um homem, um além homem, com um pensamento tão original que segue produzindo outros tantos modos de pensar, a partir de suas provocações. Assim, Zaratustra e o homem-filósofo se encontram para afirmar a vida e fazer explodir o desejo de viver em abundância por todos os lados da terra e do corpo. Assim, mais uma vez estamos diante da filosofia de Nietzsche para ruminar e continuar a pensar como ela nos toca, e o que podemos fazer com ela para tocar a vida em sua complexidade.

Em alguma medida o próprio Ecce homo é expressão do método genealógico, uma vez que nos convoca a pensar como "nos tornamos o que somos" e o que é preciso recusar para afirmar a própria vida. É preciso ser guerreiro, por vezes fazer uso do martelo, sair do conforto da vida já organizada para cultivar a si mesmo. Não significa repetir a trajetória do autor, muito menos torná-la sagrada, mas talvez incorporar processos de reflexão aprendidos em sua filosofia para dar à vida sua dimensão ética e estética. Muitas vezes para também decidir o que precisa ser rejeitado da Filosofia de Nietzsche quando reconhecida a debilidade 
de seus argumentos. Assim, ler um autor implica conhecer suas múltiplas trilhas e viagens, razões da sua indignação e de suas paixões para, afinal, cultivar as nossas próprias, se possível com a mesma originalidade.

\title{
BIOGRAPHY OR A DECLARATION OF PHILOSOPHICAL AMBITION: HOW TO READ ECCE HOMO BY NIETZSCHE
}

\begin{abstract}
This article discusses the book Ecce homo, by Nietzsche, defending that the text is an interpretation of the philosopher himself on her own thought, not to give the book a sacred tone, nor to stress his biography, but affirming a dissonant thought that indicates his philosophical ambition. With no constraints, Nietzsche presents his conflicts, passions, deceptions, announcing a tragic dimension of life that is not guided by pessimism, but by happiness of living intensely, understanding suffering as one of the facets of life. His philosophy derives from a life demand, transfigured by an experience that promotes self cultivation and the possibility of "becoming what one really is" through the "applying" of one's own genealogic method.
\end{abstract}

Keywords: Ecce homo; Philosophical Ambition; Genealogy; Self Cultivation

\section{BIOGRAFÍA O DECLARACIÓN DE AMBICIÓN FILOSÓFICA: CÓMO LEER ECCE HOMO DE Nietzsche?}

\section{Resumen}

El artículo aborda el libro Ecce Homo de Nietzsche, alegando que el texto es una interpretación de su pensamiento, para resaltar no su biografía, sino para indicar a las opiniones discrepantes y exponer su ambición filosófica. Sin restricciones, Nietzsche presenta sus conflictos, sus pasiones, decepciones, anuncia una dimensión trágica de la vida que no se dejen llevar por el pesimismo, pero la alegría de vivir intensamente, incluyendo experimentar el sufrimiento como una de las facetas de la vida. Su filosofía viene de una vida en constante devenir, transfigurada de las experiencias que promueven el cultivo de si mismo y la 
posibilidad de "llegar a ser lo que uno es" a través de la "aplicación" de su propio método genealógico.

Palabras clave: Ecce Homo; Ambición Filosófica; Genealogía; El Cultivo De Sí.

\section{REFERENCIAS}

HEIT, Helmut . Como ler ECCE HOMO - Palestra proferida no Colloquium.- Nietzsche Universidade de Berlim. Julho de 2012.

NIETZSCHE, Friedrich. Ecce homo: como alguém se torna o que é. São Paulo: Companhia das Letras, 2008.

O crepúsculo dos ídolos, ou como se filosofa com o martelo. Tradução, notas e posfácio: Paulo César de Souza. São Paulo: Companhia das Letras, 2006.

. A genealogia da moral. Petrópolis, RJ: Vozes, 2009.

. A Gaia Ciência. Trad. de Paulo César de Souza. São Paulo: Companhia das Letras, 2001.

Humano, demasiado humano. Volume II Trad. de Paulo César de Souza. São Paulo: Companhia das Letras, 2008.

O Caso Wagner/ Nietzsche contra Wagner. Trad. de Paulo César de Souza. São Paulo: Companhia das Letras, 1999.

Aurora: Reflexões sobre Preconceitos Morais. Traduzido por Mário D. Ferreira Santos. Petrópolis, RJ: Vozes, 2008.

Assim falava Zaratustra-um livro para todos e para ninguém. Tradução: Mário Ferreira dos Santos- Petrópolis, RJ: Vozes, 2007

VIESENTEINER, Jorge Luiz. Aprender a ver, aprender a pensar, aprender a falar $e$ escrever: Condições do conceito de Bildung no crepúsculo dos ídolos de Nietzsche. Artigo no prelo e disponibilizado em Palestra/UFSC-2011.

Data de recebimento: 01/05/2014

Data de aceite: 07/04/2015 